\title{
Editorial
}

\section{The Common Technical Document as academic guideline}

The Common Technical Document of the International Conference on Harmonisation $(\mathrm{ICH})$ harmonise the application procedure for drug approval. Drug approval process involves different steps, including preclinical and clinical studies, and postmarketing research for ensure the quality, safety and efficacy of medicinal products. The objective of the ICH is to reach a common understanding of the technical requirements to support the registration process. These objectives are achieved through harmonised guidelines. With the Common Technical Document (CTD), the ICH accomplish fundamental objectives. The CTD arrange the information in a common format for use in reporting the technical requirements for a new product submission to regulatory authorities.

The CTD is organized into five modules. Module 1 is for administrative information. Module 2 contains the CTD summaries. Module 3 contains information on quality topics, module 4 contains the nonclinical study reports and module 5 contains the clinical study reports.

The electronic Common Technical Document (eCTD) facilitate electronic submissions. The eCTD suppose a major advance in the submission of information to support a new drug application.

The CTD are, too, one major step in the process of general globalisation of the law of medicinal products in the development of the legal status of medicinal products.

The Community Code relating to medicinal products contains all current provisions in matters of production, marketing, distribution and utilization of medicinal products for human use. This Code include The Common Technical Document.

Since the signing of the Treaty of Rome, in addition to its general political aims, the European Community has set out the free movement of persons, goods and capital, to achieve a single market, in the perspective of a political Union. Each one of those steps was not easy. The technical harmonisation of goods was required, and for goods as special as medicinal products, the difficulties to overcome were so numerous that we are still trying to make the system perfect. In the field of free movement of persons, the health care professions of doctors, pharmacists, nurses and veterinary has been no easy task, as it has been necessary to harmonise studies and then to proceed to the mutual recognition of qualifications.

A range of Community measures is aimed at facilitating the free movement of people. Most importantly, a set of specific directives has been established governing the recognition of diplomas for individual health professions. This system is intended to allow health professionals (doctors, nurses, pharmacists, etc.) to take up work in 
another Member State while avoiding major difficulties related to registration and recognition.

To tackle these obstacles, the EU has introduced several instruments, aimed at facilitating the transfer of academic and professional qualifications and competencies. The free movement of pharmacists takes place within the basic freedoms of the European Union: free movement of persons, freedom of establishment, freedom of services and free circulation of medicines as goods. Specifically, the first system of mutual recognition of degrees in the pharmaceutical sector was carried out within the framework of the harmonisation of free circulation of drug products for those pharmacists in the pharmaceutical industry with the legal status of "qualified person", in Directive 75/319/EEC. A further ten years passed before the free establishment of both community and hospital pharmacists was recognized. This was carried out through two complementary directives, Directive 85/432/EEC on the coordination of certain pharmaceutical activities and Directive 85/433/EEC, concerning the recognition of the right of establishment for pharmacists. The first Directive on the coordination of activities has been very important because it delimited recognized pharmaceutical activities; the requirements for the granting of degrees; the minimum duration of the formal training cycle and the essential matters to be included in the syllabus.

More recently, Directive 2001/19/EEC, introduced a new strategy dealing with the problems of qualifications in all health professions: nurses responsible for general care, dentists, veterinary surgeons, midwives, pharmacists and doctors. Thus, a single text was obtained.

For the purposes of equivalence in qualifications, this proposal sets minimum training conditions for the different professions including pharmacists. Admission to a training course as a pharmacist shall be contingent upon possession of a diploma or certificate giving access, for the studies in question, to universities or higher institutes of an equivalent level, and shall include training of at least five years duration, including at least four years of full-time theoretical and practical training at a university and a six-month traineeship in a pharmacy which is open to the public or in a hospital.

In this area of delimitation of the essential matters to be included in the syllabus for the minimum training which should be taught in essential areas in the pharmaceutical studies, the consideration of the content of The Common Technical Document, will be essential. For this reason on will consider The Common Technical Document as one fundamental Guideline for the core of the essential matters included in the academic programs.

All the professors and all the disciplines participated in the minimum training for pharmaceutical degrees will incorporated this matter in his programs.

In this orientation, the Monograph of Pharmaceuticals Policy and Law, have the fundamental objective for facilitate one didactic guide for better comprehension of the content of The Common Technical Document, as essential description of all the 
scientific and technical dimension of the medicinal product. The pharmacist are as specific and basic objective to knowledge all the dimensions of medicinal products.

In the preparation of this didactic guide have participated specialists of all the area of pharmaceutical knowledge. The members of the Ibero-american Academy of Pharmacy (Academia Ibero-americana de Farmacia) and other Scientifics had participated very generously. We thanks very much all the collaboration, included the special contribution of the Dr. Fernand Sauer, Former Director of the European Medicinal Agency, and promoter active, contributor and witness of exception of all the phases of the process of ICH Conference and his results, included the essential achievement of The Common Technical Document.

Prof. José Luis Valverde and Prof. Alberto Ramos-Cormenzana Editors 